PREPARED FOR THE U.S. DEPARTMENT OF ENERGY, UNDER CONTRACT DE-AC02-76CH03073

PPPL-3479

PPPL-3479

UC-70

A Study of Cylindrical Hall Thruster for Low Power Space Application

by

Y. Raitses, N.J. Fisch, K. Ertmer, and C.B. Burlingame

July 2000

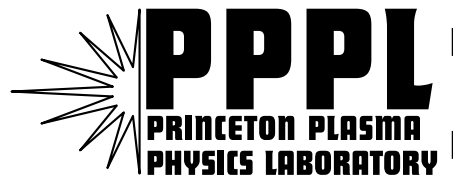

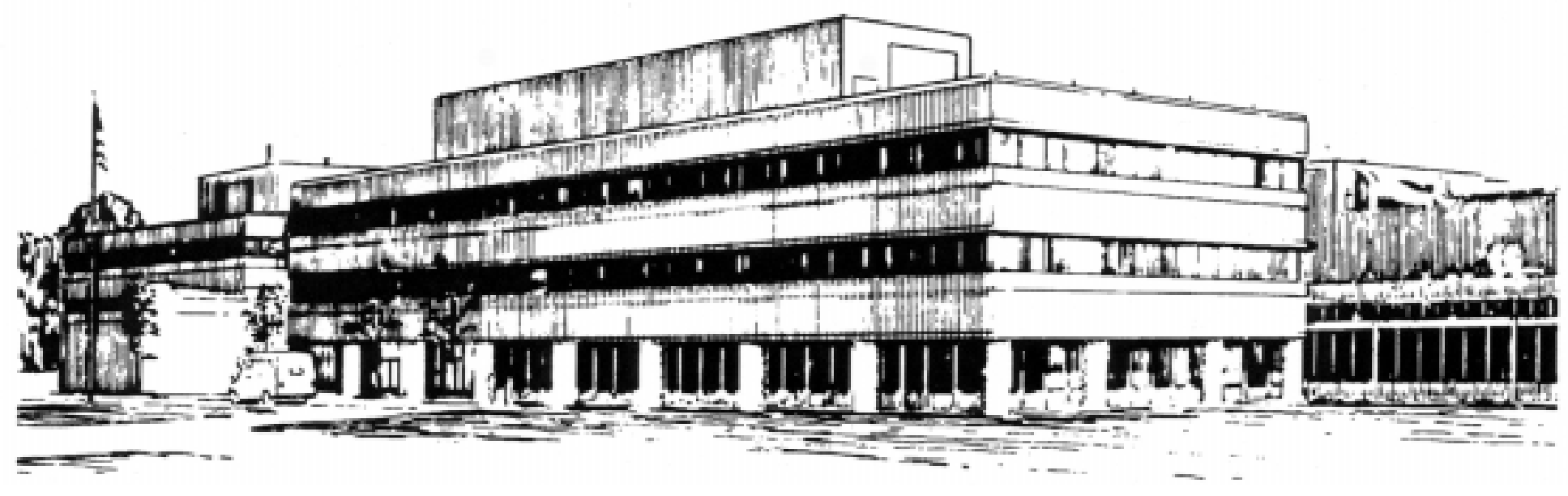

PRINCETON PLASMA PHYSICS LABORATORY PRINCETON UNIVERSITY, PRINCETON, NEW JERSEY 


\section{PPPL Reports Disclaimer}

This report was prepared as an account of work sponsored by an agency of the United States Government. Neither the United States Government nor any agency thereof, nor any of their employees, makes any warranty, express or implied, or assumes any legal liability or responsibility for the accuracy, completeness, or usefulness of any information, apparatus, product, or process disclosed, or represents that its use would not infringe privately owned rights. Reference herein to any specific commercial product, process, or service by trade name, trademark, manufacturer, or otherwise, does not necessarily constitute or imply its endorsement, recommendation, or favoring by the United States Government or any agency thereof. The views and opinions of authors expressed herein do not necessarily state or reflect those of the United States Government or any agency thereof.

\section{Availability}

This report is posted on the U.S. Department of Energy's Princeton Plasma Physics Laboratory Publications and Reports web site in Calendar Year 2000. The home page for PPPL Reports and Publications is: http://www.pppl.gov/pub_report/

DOE and DOE Contractors can obtain copies of this report from:

U.S. Department of Energy

Office of Scientific and Technical Information

DOE Technical Information Services (DTIS)

P.O. Box 62

Oak Ridge, TN 37831

Telephone: (865) 576-8401

Fax: (865) 576-5728

Email: reports@adonis.osti.gov

This report is available to the general public from:

National Technical Information Service

U.S. Department of Commerce

5285 Port Royal Road

Springfield, VA 22161

Telephone: $1-800-553-6847$ or

(703) $605-6000$

Fax: (703) 321-8547

Internet: http://www.ntis.gov/ordering.htm 


\title{
A Study of Cylindrical Hall Thruster for Low Power Space Applications
}

\author{
Y. Raitses and N.J. Fisch, K.M. Ertmer, and C.A. Burlingame \\ Princeton Plasma Physics Laboratory, Princeton University \\ P.O. Box 451, Princeton, NJ 08543
}

\begin{abstract}
$\underline{\text { Abstract }}$
A $9 \mathrm{~cm}$ cylindrical thruster with a ceramic channel exhibited performance comparable to the state-of-the-art Hall thrusters at low and moderate power levels. Significantly, its operation is not accompanied by large amplitude discharge low frequency oscillations. Preliminary experiments on a $2 \mathrm{~cm}$ cylindrical thruster suggest the possibility of a high performance micro Hall thruster.
\end{abstract}

\section{Introduction}

Miniature or constellations of miniature satellites may reduce the cost of various space missions [1-3]. To propel these satellites requires small and micro electric thrusters, operating efficiently at low input power levels $(<500 \mathrm{~W})$, with large propellant mass savings relative to chemical rockets and electrothermal thrusters. Large specific impulse (1000-2000 sec) and efficient $(50 \%)$ Hall thrusters [4] would be useful for near earth low power space applications. However, existing scaled-down low-power Hall thrusters appear to be much less efficient than their large counterparts operating at powers larger than 0.5 $\mathrm{kW}[5,6]$.

It is likely that the poor performance of small Hall thrusters is mostly due to the necessarily non-optimal profile of the magnetic field produced in the small coaxial channel. The physical constraints in making a miniaturized magnetic circuit include magnetic saturation and Curie temperature of materials used in the circuit (such as low carbon iron or cobalt samarium). A linear scaling down of the magnetic circuit leaves almost no room for use of magnetic

Copyright@2000 by the American Institute of Aeronautics and Astronautics Inc. All rights reserved. screens and thin magnetic poles, as well as for heat shields to implement a magnetic field distribution with an optimized axial gradient, similar to that in high performance large Hall thrusters [7]. The non-optimal magnetic field results in enhanced power and ion losses, heating and erosion of thruster parts, particularly the critical inner parts of the coaxial channel and magnetic circuit. Thus, the implementation of a highly efficient micro Hall thruster with a conventional coaxial geometry is not likely practical.

An alternative to coaxial Hall thrusters, the endHall thruster, better known as Kaufman s ion source, has a cylindrical configuration with no inner parts of the channel and magnetic circuit [8-10]. The magnetic field is similar to the fringing field of a solenoid. In variations of this thruster, the magnetic field lines can intersect or be almost parallel to the anode surface $[8,9]$. Where the magnetic field lines intersect the anode [8], the electrons can diffuse towards the anode along these lines. In any event, the electrons rotate along closed drift trajectories in the $\mathrm{E} \times \mathrm{B}$ direction, similar to coaxial Hall thrusters. Since the magnetic field of end Hall thrusters has a strong axial component, there appears a radial electric field, which doesn $t$ contribute directly to the thrust, but does produce a large beam divergence [9]. Also, since these thrusters employ metal channel walls, the electron transport towards the anode can be enhanced by hot electrons, which are not cooled down by secondary emission as they would be in the case of SPT thrusters with ceramic walls [11]. End Hall thruster are thus typically characterized by a larger discharge current than coaxial thrusters. Parametric measurements of end Hall thrusters demonstrated very low performance $(10-20 \%)$ and larger plume compared to coaxial Hall thrusters at even the moderate power levels of about $500 \mathrm{~W}$. 
The ability of coaxial Hall thrusters to achieve high performance at moderate power levels and the simplicity of the scaling and miniaturization of end-Hall thrusters suggest a combination of these thruster approaches, which we call a Cylindrical Hall Thruster (CHT). The results, described in this paper, already demonstrate the ability of laboratory CHT thrusters to achieve high performance, comparable to state-of the-art Hall thrusters, in the $0.1-1 \mathrm{~kW}$ power range.

\section{Design of laboratory CHT thrusters}

The principle of operation of CHT thruster is illustrated in Fig. 1. The thruster consists of cylindrical ceramic channel, ring-shaped anode, which can also be a gas distributor, the magnetic core and magnetized sources. The magnetic field lines intersect the ceramic channel walls. The electron drifts are closed, with the magnetic field lines forming equipotential surfaces. The ratio between the axial and radial components of the magnetic field can be controlled through the number, sizes and shapes of the magnetic poles, as well as through distance between them. Several magnetized sources can be used to control the magnetic field distribution.

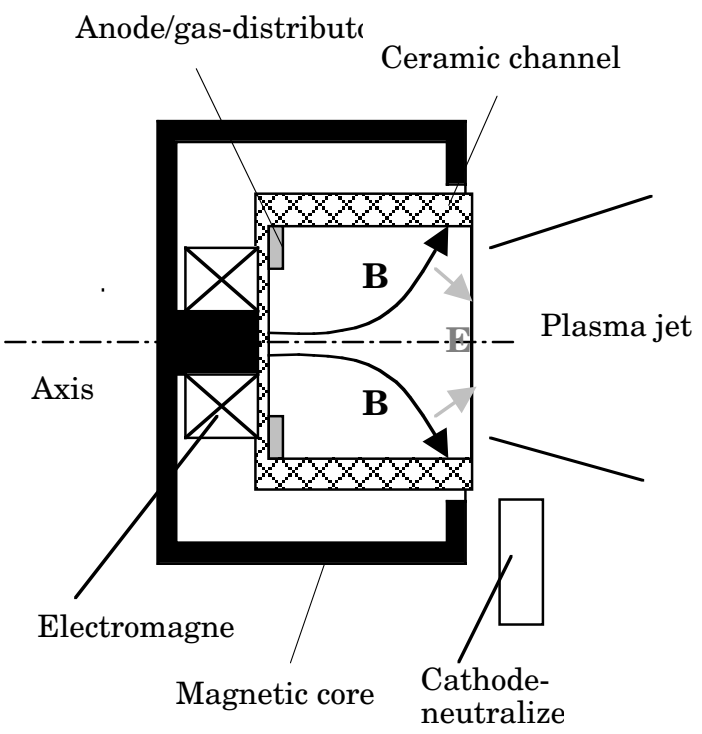

Fig. 1 Schematic drawing of the cylindrical Hall thruster.

The key differences distinguishing the cylindrical geometry thruster from the end-Hall thrusters are one, the shape of the magnetic field lines, which can have stronger radial component without intersecting the anode; and, two, the use of ceramic walls, restrains the electron temperature below the first threshold of the secondary electron emission. Moreover, specific implementations can make use of programming the potential profile through segmented electrodes [12]. In implementations pursued here, the gas inlet is off-axis to decouple it from the anode potential surface.

The first studies of the micro CHT thruster employed large models, which are likely more easily diagnosed and understandable than the scaled down thruster. Two large CHT thruster designs with different magnetic circuit configurations have been studied and implemented as laboratory prototypes. The magnetic circuits are different in the number of coils and diameter of the inner pole. The $9 \mathrm{~cm}$ laboratory PPPL thruster has modular magnetic circuit and boron nitride ceramic channel (Fig. 2 ). A coaxial version of this thruster has been used in studies of the segmented electrode Hall thruster, as reported in Ref. [12,13].

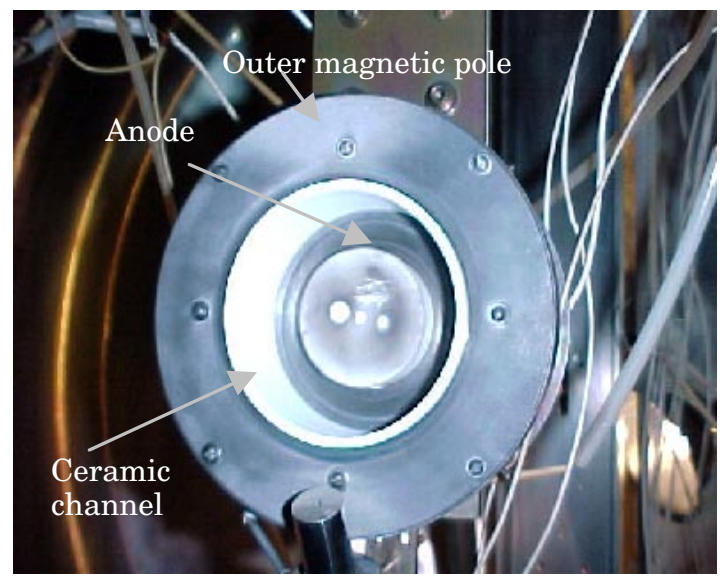

Fig. 2 A $9 \mathrm{~cm}$ laboratory CHT thruster.

The single coil CHT configuration produces the magnetic field shown in Fig. 3. The inner coil is placed on the inner rod behind the channel. The channel, indicated by solid gray lines, connects a $1 \mathrm{~cm}$ long coaxial region, in which the anode is located, to a $3.5 \mathrm{~cm}$ long cylindrical region. The outer magnetic pole is about $0.5 \mathrm{~cm}$ behind the channel edge. The maximum of the radial magnetic field is somewhere near the boundary of the regions. In principle, the movable anode can be placed at this boundary to construct a 
purely cylindrical channel. However, azimuthal waves may be unstable for $\partial(B / n) \partial z<0$ [7], where $B$ is the magnetic field, $n$ is the plasma density and $\mathrm{z}$ is axial coordinate. Thus, a short coaxial channel part with a magnetic field magnitude increasing towards the boundary of two regions may lead to more quiet operation. The length of the coaxial region was selected to provide effective ionization in this region [14]. The scaling of the mass flow rate and cross sectional dimensions of the CHT is likely similar to the coaxial thruster $[4,15]$. If so, the $9 \mathrm{~cm}$ CHT thruster should be able to operate at the same mass flow rates as its coaxial counterpart $(2-3 \mathrm{mg} / \mathrm{s})$.

The magnetic circuit with two (outer and inner) electromagnet coils gives more flexibility and control of the magnetic field. Figs. 4 and 5 show the results of magnetic field simulations of this magnetic circuit. In addition, a small inner magnetic pole is added here to increase the magnetic field magnitude at the boundary between coaxial and cylindrical regions. Note that the outer coil with the current opposite to the inner coil creates the region with the axial magnetic field near the thruster exit. Such a lens configuration is somewhat similar to the plasma optical system suggested by A. I. Morozov for focusing of compensated beams [16].

A $2 \mathrm{~cm}$ laboratory micro CHT thruster ( Fig. 6), was designed, as a preliminary research tool, to study the feasibility of miniaturization of cylindrical Hall thrusters. Its channel and poles were scaled down linearly relative to the large CHT thruster. The scaling was targeted for the power range of $100-200 \mathrm{~W}$.

To reduce the heating of the micro thruster parts and to prevent saturation of magnetic circuit parts, the magnetic poles and ceramic channel are the only scaled down parts. The other thruster parts have enlarged sizes integrated with the miniaturized channel and poles. In the present design, an electromagnet coil is used as the magnetized source to provide flexibility and control of the magnetic field.

The micro thruster is assembled on a 8 conflat flange and can be placed outside the vacuum chamber, while the channel, anode and cathode are under the vacuum. Such an outside assembly of the thruster is easy for maintenance, convenient for experiments, and is amenable to convective cooling by air during the thruster operation.

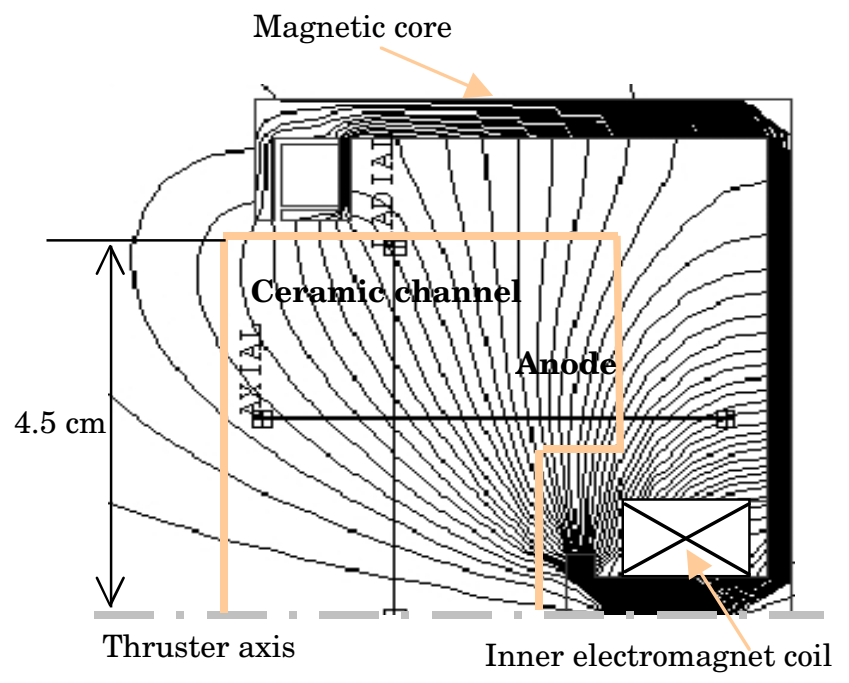

Fig. 3 Non linear magnetic field simulations for the single coil CHT configuration.

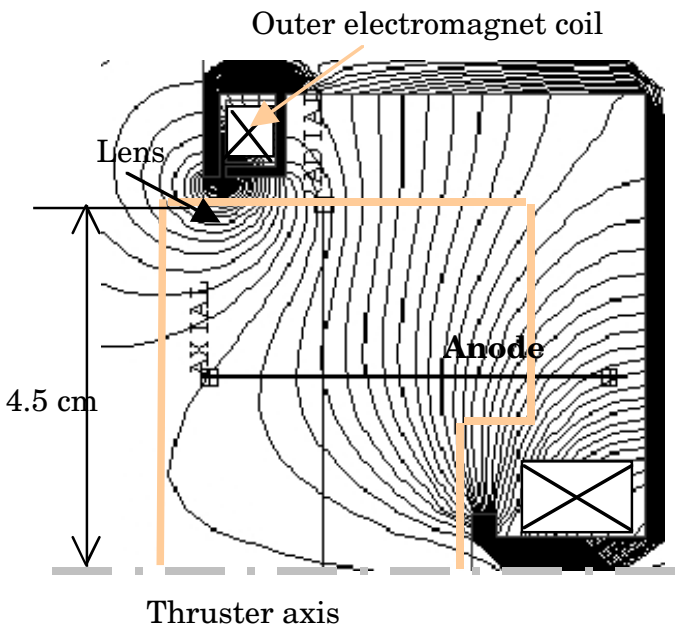

Fig. 4 Non linear magnetic field simulations for two coil CHT configuration.

\section{Test facility and diagnostic setup}

Experiments with a $9 \mathrm{~cm}$ laboratory CHT thruster took place in a $28 \mathrm{~m}^{3}$ vacuum vessel pumped down with 35 diffusion pump. The measured pumping speed for Xenon is 13,000 1/s. Further details about this facility and other utilities can be found in Ref. [12,13]. In addition to a $0.5 \mathrm{mN}$ thrust resolution thrust stand, flat movable probe for plume measurements, ac and dc power measurements and flow meters, thruster diagnostics include seven cylindrical 
Langmuire probes made of $0.5 \mathrm{~mm}$ thoriated tungsten wire. The probes were placed along the outer channel wall in both coaxial and cylindrical regions. Each probe has approximately a $1 \mathrm{~mm}$ long opened wire path exposed to the plasma.

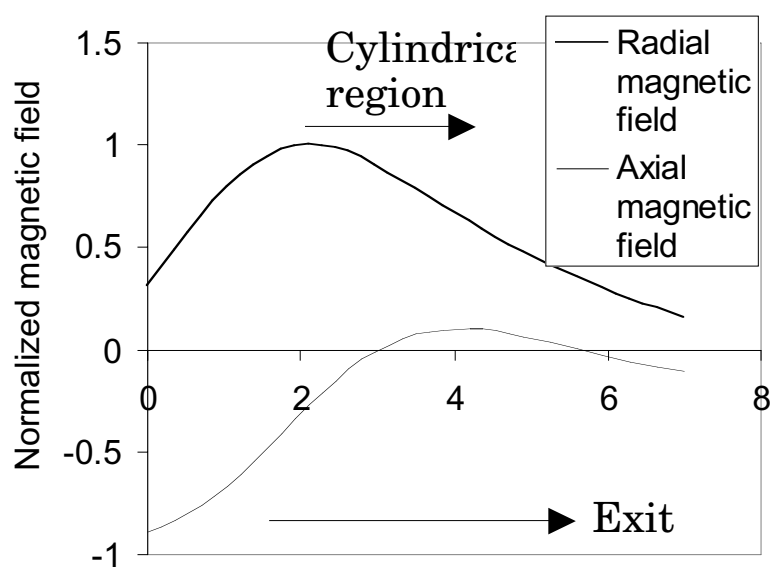

Thruster axis, cm

Fig. 5 Axial profiles of the radial and axial components of the magnetic field normalized to the maximum vale of the radial magnetic field.

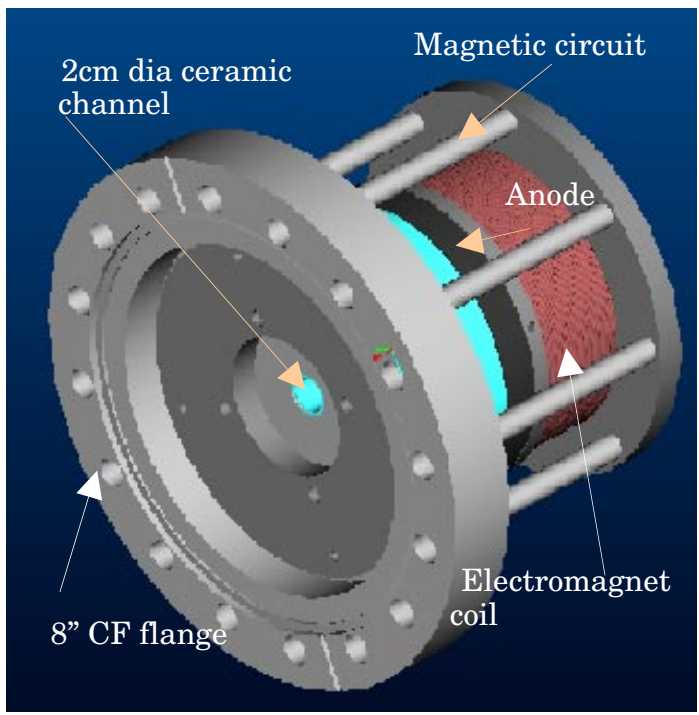

Fig. 6 Design of a $2 \mathrm{~cm}$ laboratory micro CHT thruster.

Probe V-I characteristics were measured by biasing from a bipolar Kepco power supply controlled by a swept generator. The plasma potential was derived from a differentiated I-V characteristic [17].

Fig. 7 shows a $2 \mathrm{~cm}$ laboratory micro $\mathrm{CHT}$ thruster mounted on a $0.3 \mathrm{~m}^{3}$ vacuum chamber. equipped with a $1500 \mathrm{l} / \mathrm{s}$ (for air) turbo pump. The measured background gas pressure at a xenon flow of 5 SCCM is 0.3 millitorr that corresponds to a xenon pumping speed of 200 $1 / \mathrm{s}$. High background pressure can affect the Hall thruster operation since additional xenon gas can enter through the thruster exit [14]. Nevertheless, using a turbo pump avoids arcing phenomena and other difficulties of the thruster and cathode start/run, due to the absence of oil contamination. A commercial HeatWave-250 hollow emitter was used as the cathode neutralizer. Diagnostics of this set of micro thruster experiments were constrained by the resolution of electrical and mass flow rate measurements.

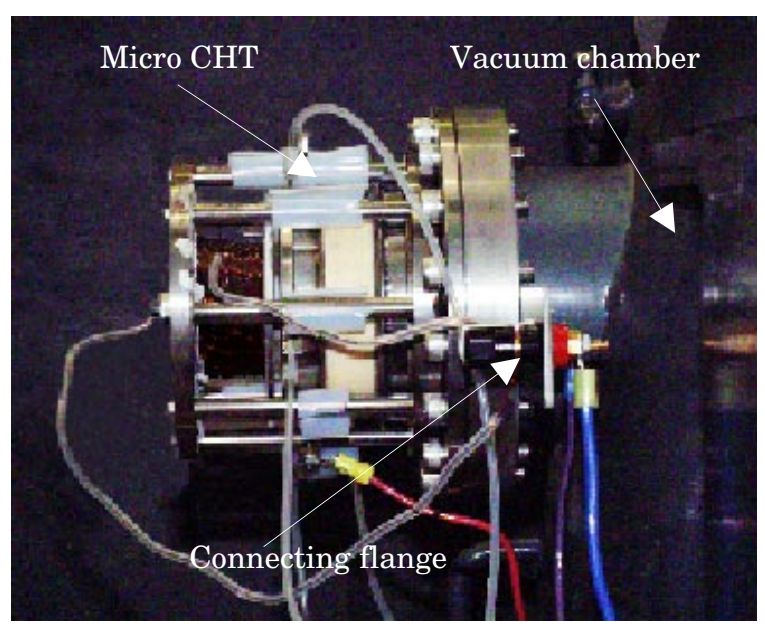

Fig. 7 A $2 \mathrm{~cm}$ laboratory micro thruster assembled on the small vacuum chamber

\section{$\underline{\text { 4. Results and analysis }}$}

A $9 \mathrm{~cm}$ laboratory CHT thruster was operated at xenon mass flow rates of $1-2.5 \mathrm{mg} / \mathrm{s}$ and discharge voltage of $70-300 \mathrm{~V}$ with single and two coil configurations of the magnetic circuit. Fig. 8 shows operation of the single coil CHT thruster. Generally, the CHT thruster of either configuration operated very stably at mass flow rates of less than $1.7 \mathrm{mg} / \mathrm{s}$. However, since the best performances were measured with the two coil CHT case, the results of this thruster are described below. 
Note, that stable operation of the $9 \mathrm{~cm}$ coaxial Hall thruster at such small mass flow rates was apparently not achievable.

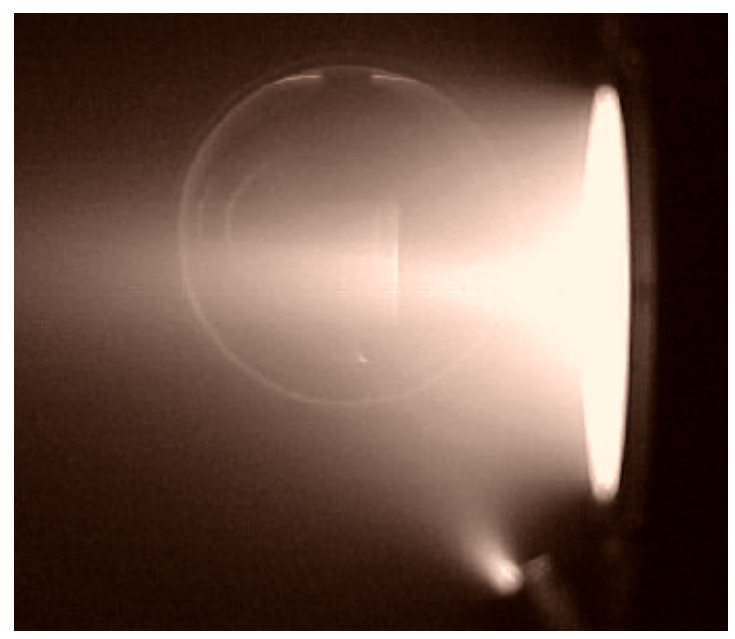

Fig. 8 Operation of a $9 \mathrm{~cm}$ CHT thruster with single coil configuration.

First, consider the plasma and floating potentials, shown in Fig. 9, for different values of the coils current (magnetic field). As can be seen, the voltage potential drops in the coaxial and cylindrical regions of the channel are almost equal, while the electric field is somewhat larger in the coaxial region, roughly by $\mathrm{L}_{2} / \mathrm{L}_{1}$, where $\mathrm{L}_{1}$ and $L_{2}$ are the lengths of the coaxial and cylindrical regions. This could be due to a large radial magnetic field magnitude in the coaxial region (See Fig. 4), impeding the electron diffusion towards the anode. Thus, the ion acceleration takes place in both coaxial and cylindrical regions of the channel. We estimated that the residence time of ions in the coaxial channel and cylindrical channel are proportionately roughly $0.4 \mathrm{~L}_{2} / \mathrm{L}_{1}$. Hence, as can be seen from Fig. 9, the residence time in each region depends on the ratio of the coils currents. For example, at the regimes with so-called optimal magnetic fields, as described below, it takes a longer time for the ions to move through the cylindrical region than through the coaxial. As a result, it may be necessary to control the focusing of the ion beam in this region by a magnetic circuit configuration or by segmented electrodes [12]. For this purpose, the CHT thruster has more flexibility than Hall thrusters with an outside electric field, in which the ion acceleration takes place mainly across a fringing magnetic field [18].
A relatively small jump of the potential near the channel exit (See Fig. 9) may be attributed to different mobility of electrons and ions across the axial magnetic field. The curved magnetic field lines enable electrons to diffuse from the cathode to the outer channel wall. As a result, the plasma potential drops at the intersection of the field lines with the channel walls. A strong axial component of the magnetic field ( 200 Gauss, $\mathrm{R}_{\mathrm{Le}} \sim 0.3 \mathrm{~mm}<$ height of the lens) impedes electrons from reaching the walls across magnetic field, but not along the field lines. On the other hand, non magnetized ions, which are accelerated to the walls by the radial electric field, can still penetrate across the axial magnetic field. Hence, they build up a positive potential at the wall, relative to the bulk plasma. Of course, the total current to the dielectric walls must be zero. This interesting behavior, possibly useful for ion beam focusing, merits further study.
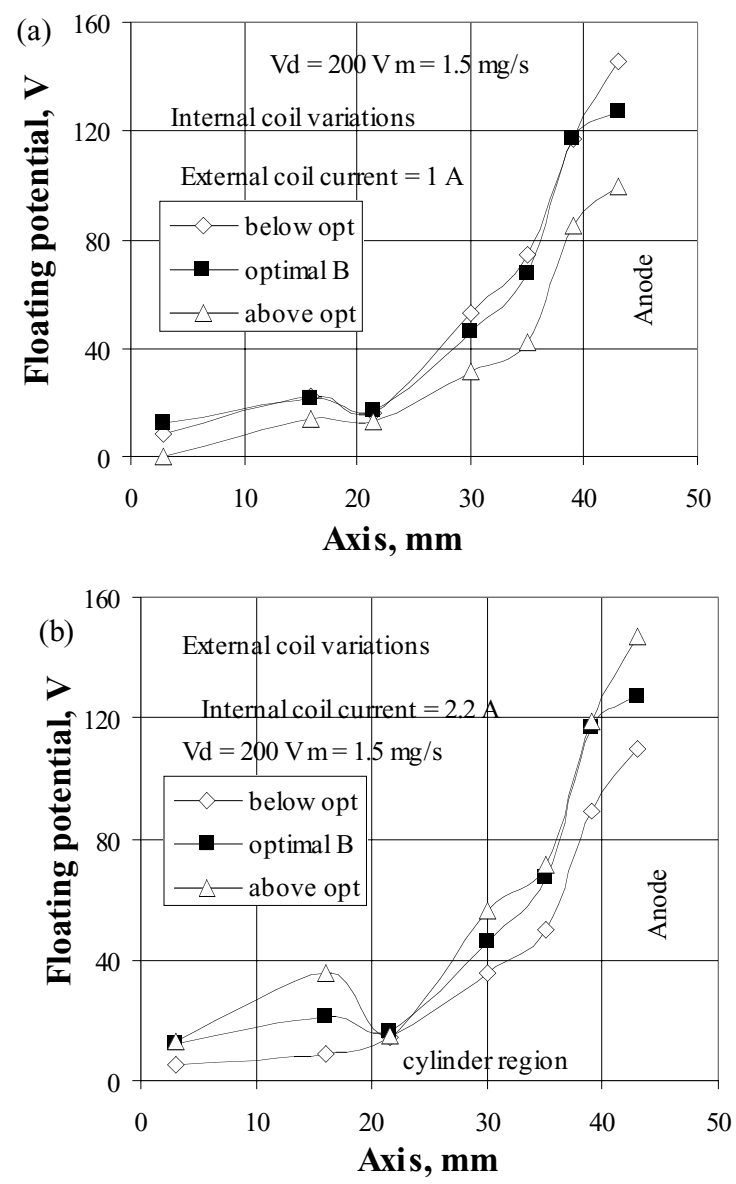

Fig. 9 Floating potential measured relative to the cathode along the outer channel wall under coils current variations. While varying the current in one coil, the current in the other coil is constant. 
Note, that the potential distributions of Fig. 9 were measured at $200 \mathrm{~V}$, while the maximum value of the plasma potential near the anode is less. This result is might also be attributed to the curvature of the magnetic field lines in the coaxial region that affects radial electric field towards the outer wall.

Some illustrative curves of the discharge current versus the magnetic field at various values of the mass flow rate and at a constant discharge voltage of $250 \mathrm{~V}$ are shown in Fig. 10.

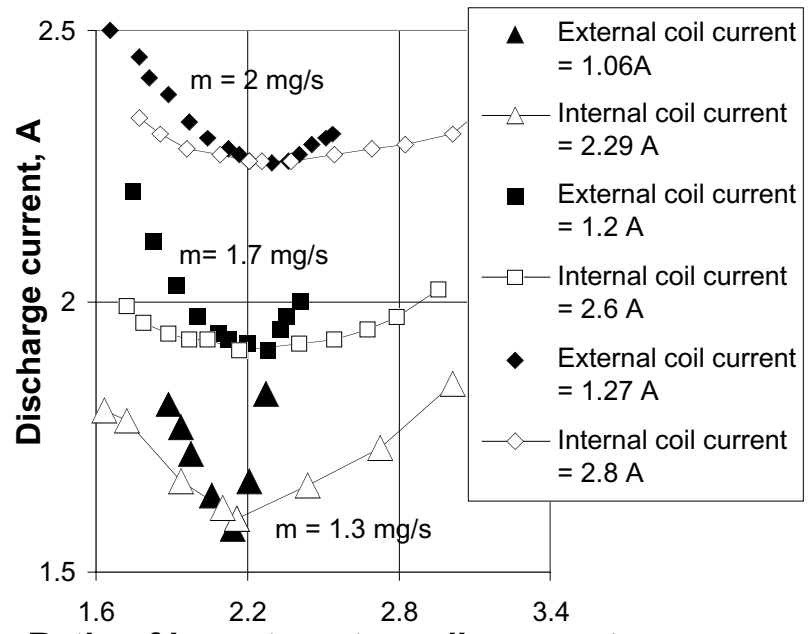

Ratio of inner to outer coils currents

Fig. 10 Effect of the magnetic field (current in the inner and outer coils and their ratio) on the discharge current.

Like for conventional coaxial Hall thrusters, there exists an optimal magnetic field with a distinct distribution of currents in the coils. Indeed, since the magnetic field impedes the axial electron current, the discharge current should tend to scale inversely with the magnetic field. However, above a certain value of the magnetic field (or rather the ratio of currents in the coils), the discharge current increases again. Fig. 10 shows that the discharge current is more sensitive to variations in the inner coil current, which contributes to the magnetic field maximum at the boundary of the channel regions. In addition, as the mass flow is reduced, the effect of both coils becomes more significant.

Interestingly, in contrast to the behavior of coaxial Hall thrusters, the increase of the discharge current in the CHT is not accompanied by low frequency discharge oscillations. In conventional thrusters, these oscillations $(10-20$ $\mathrm{kHz}$ ) result from ionization waves, which affect the discharge current [19]. As can be seen in Fig. 11, thruster is relatively quiet. This surprising result, which is not understood at the moment, may be an indication of electron transport towards the gas distributor (anode) enhanced by the presence of a stronger axial magnetic field.

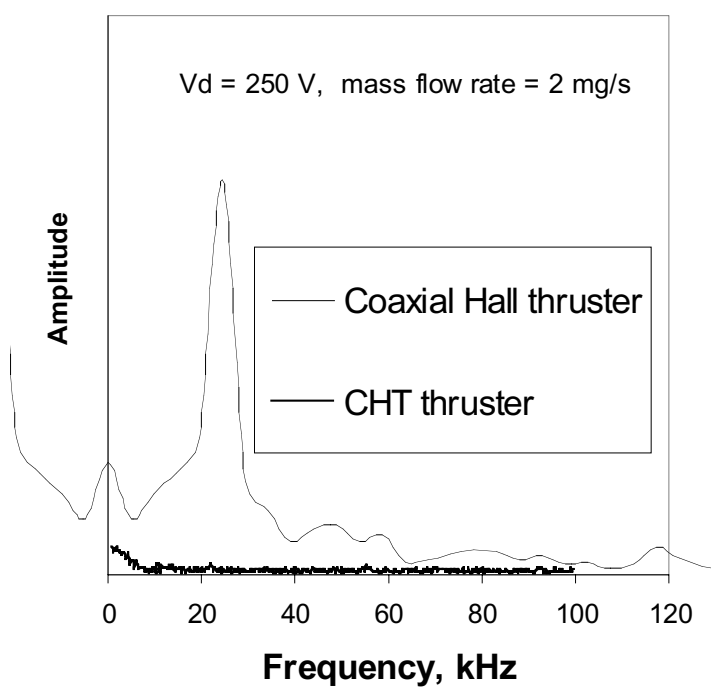

Fig. 11 The measured spectrum of the CHT.

Perhaps changes in the voltage potential distribution may help to explain the behavior of the discharge current versus the magnetic field. As can be seen in Fig. 9, increasing the coil current ratio above its optimal value, shifts the voltage potential drop towards the anode. The ionization then would take place closer to the anode, reducing the traveling time of atoms before ionization. In addition to wall collisions, electrons can then more easily escape from the ionization region with a strong axial component of magnetic field to the anode, thus increasing the discharge current.

Figs. 12-14 compare integral characteristics of the CHT thruster and coaxial Hall thruster. Each point on these figures corresponds to the measured minimum of the discharge current versus the magnetic field. Both propellant utilization and thruster efficiency were estimated with no cathode flow rate. 


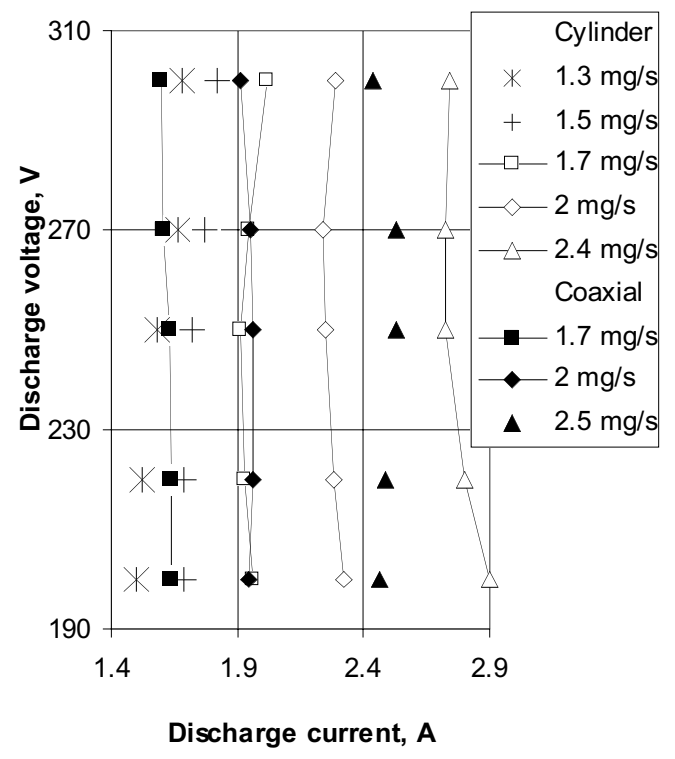

Fig. 12 V-I characteristics measured for cylindrical and coaxial Hall thrusters.

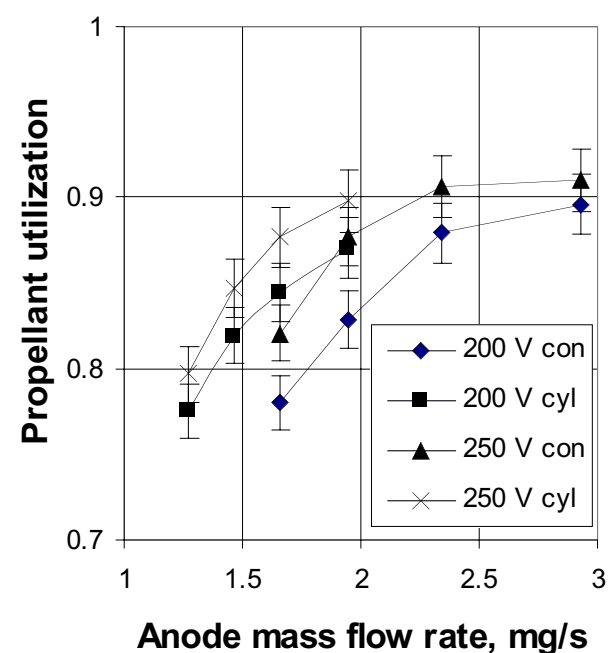

Fig. 13 Propellant utilization versus the discharge voltage measured for cylindrical and coaxial Hall thrusters.

Although V-I characteristics of the CHT thruster are similar to the coaxial thruster case, they are shifted towards larger values of the discharge current at each operating point (Fig. 12). Since improvements in the propellant utilization of the CHT thruster (Fig. 13) at $1.7 \mathrm{mg} / \mathrm{s}$ and $2 \mathrm{mg} / \mathrm{s}$ are relatively smaller, this shift of the V-I characteristics is mainly due to larger axial electron current compared to the coaxial thruster. Note that the presence of the radial electric field in the CHT thruster should affect wall losses, but probably not enough to mitigate improvements in the propellant utilization. An increase of the electron current may be caused by the near anode location of the ionization region in the presence of a strong axial magnetic field (Fig 4).

As for the thruster performance, larger propellant utilization in the CHT case produces larger thrust (Fig. 14a). In general, although the coaxial thruster is more efficient (Fig. 14b) both types of Hall thruster demonstrate comparable thrust and thruster efficiency.

a)

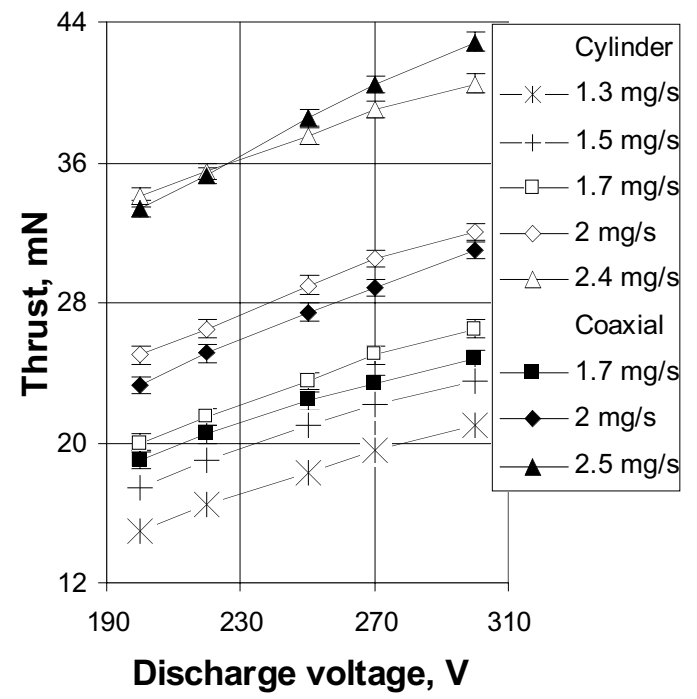

b)

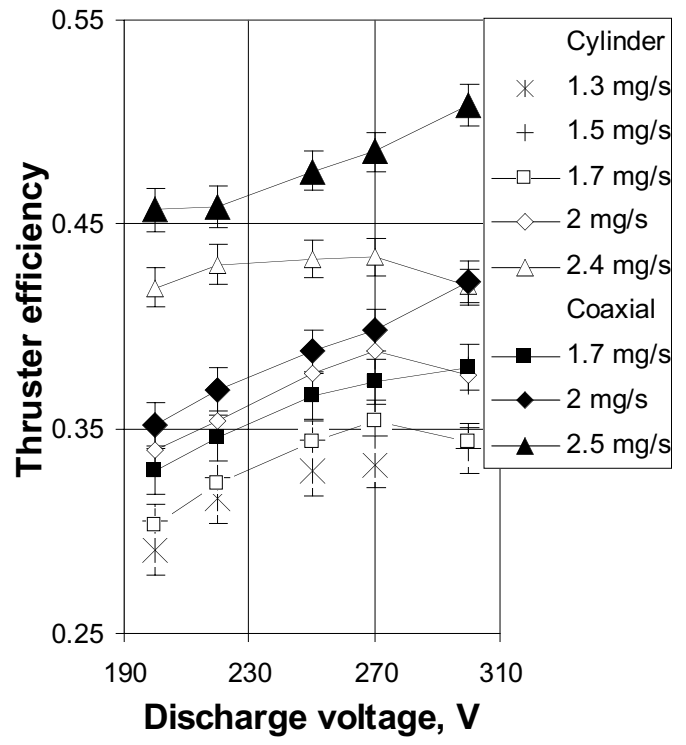

Fig. 14 Thrust (a) and thruster efficiency (b) versus discharge voltage measured for cylindrical and coaxial Hall thrusters. The cathode flow rate is not taking into account. 
Finally, some preliminary illustrative results obtained with a $2 \mathrm{~cm}$ laboratory micro CHT thruster and their comparison with the large CHT thruster are illustrated in Figs. 15-17. The micro thruster was successfully operated at a power range of $50-360 \mathrm{~W}$ (see Figs. 15,16). So far, 4 hours of operation were accumulated. In contrast to the large CHT, there were no indications of the existence of an optimal magnetic field. While increasing the magnetic field, the discharge current reduces until the thruster is suddenly turned off. At $0.2 \mathrm{mg} / \mathrm{s}$, the discharge current is less affected by the discharge voltage than at the larger mass flow rate. Nevertheless, at both mass flow rates the ratio of the discharge current to equivalent mass flow current is larger than that measured with $9 \mathrm{~cm}$ CHT and coaxial thrusters (Fig. 17). As can be seen in the case of an efficient coaxial and two coils CHT thrusters, the mass flow current should be just somewhat less than the discharge current. Therefore, the results of Fig. 17 suggest the existence of strong electron diffusion across the magnetic field to the anode.

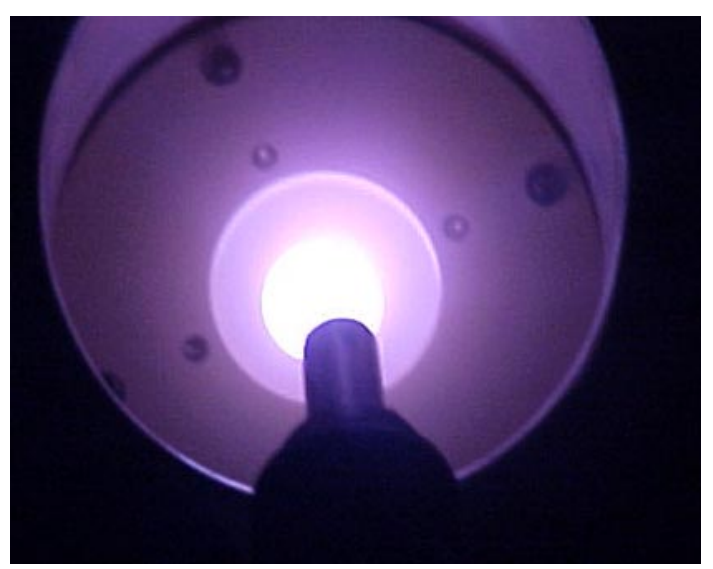

Fig. 15 Operation of a $2 \mathrm{~cm}$ laboratory micro cylindrical Hall thruster of the single coil configuration.

Note that, at $0.2 \mathrm{mg} / \mathrm{s}$, the current ratio obtained with the micro thruster is close to that measured with the single coil CHT thruster of larger diameter. On the other hand, the use of two coils exhibited better results in terms of the current ratio and performance. It seems reasonable to expect that use of two coils might also be beneficial for the micro thruster.

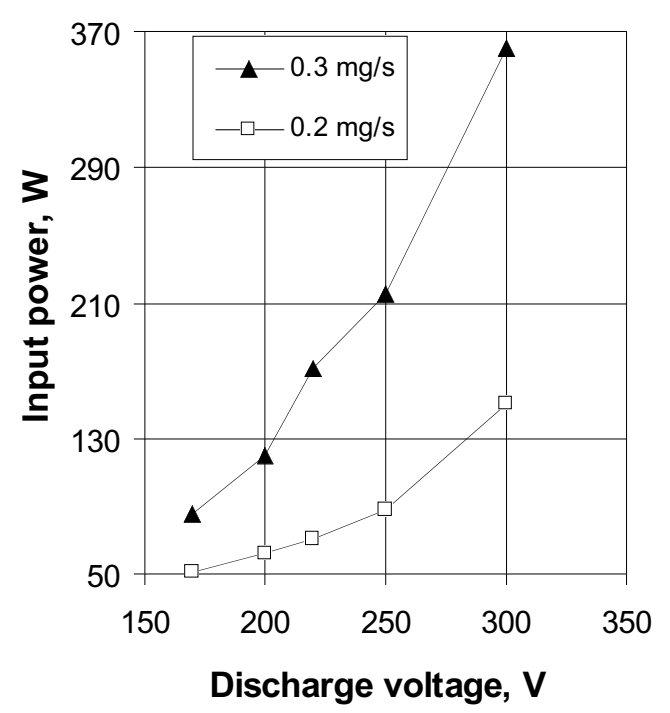

Fig. 16 Input power of the micro CHT thruster as function of the discharge voltage at mass flow rate of $0.2 \mathrm{mg} / \mathrm{s}$ and $0.3 \mathrm{mg} / \mathrm{s}$.

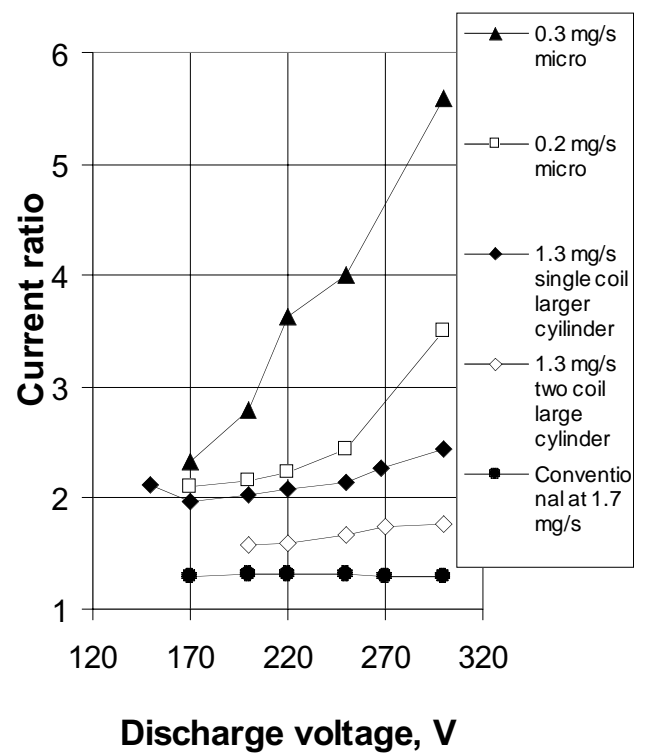

Fig. 17 The ratio of the discharge current to the equivalent mass flow current (A) for four different thrusters: $2 \mathrm{~cm} \mathrm{CHT,} 9 \mathrm{~cm}$ single coil CHT, $9 \mathrm{~cm}$ two coil CHT and conventional coaxial Hall thruster. 


\section{Summary}

The Hall thruster, with a channel featuring both coaxial and cylindrical regions, apparently achieves higher performance and better focusing than end Hall thrusters. In addition, the absence of the inner thruster parts at the end of the acceleration region can lead to reduced wall losses and, as a result, to increase lifetime as compared to conventional coaxial Hall thrusters. These advantages can be particularly useful for implementation of high performance small and micro Hall thrusters.

When the maximum of the magnetic field is at the boundary of the coaxial and cylindrical regions, two acceleration regions of almost the same length are established along channel. As a result of lower ion energy at the boundary between the two regions, less erosion and heating of the shortened inner wall and magnetic parts might be expected. The use of two electromagnet coils with opposite currents and certain magnetic poles allows the establishment of a favorable magnetic field distribution with a strong radial component in most of the channel. It also allows for a focusing B field with strong axial component at the thruster exit. A cylindrical laboratory Hall thruster with such a configuration of the magnetic field demonstrated the ability to operate at smaller mass flow rates than coaxial thruster of the same diameter. At large mass flow rates, the performance of the cylindrical thruster comparable to the state of the art coaxial Hall thrusters. A set of experiments with a micro cylindrical Hall thruster proved the feasibility of miniaturization of the cylindrical Hall thruster with operation at power levels of $50-200 \mathrm{~W}$.

One of the most interesting experimental observations is very quiet operation of the cylindrical thruster without large amplitude oscillations in low frequency range. This result, which may simplify the matching of the cylindrical Hall thruster with a power processing unit, is likely a significant finding.

\section{Acknowledgement}

The authors benefited from discussions with Andrei Litvak, Leonid Dorf and Prof. Amnon Fruchtman. Thanks also to Tim Graves and Rick Williams for their assistance in experiments.

This work has been supported by AFOSR.

\section{$\underline{\text { References }}$}

1. R. A. Spores and M. Birkan, The USAF Electric Propulsion Program, AIAA paper 983181, July 1998.

2. S. W. Janson, Chemical and Electric Micropropulsion Concepts for Nanosatellites, AIAA paper 94-2998, June 1994.

3. G. S. Yashko and D. E. Hastings, Analysis of Thruster Requirements and Capabilities for Local Satellite Clusters, AIAA paper, 1996

4. M. Martinez-Sanchez and J. E. Pollard, Spacecraft Electric Propulsion-An Overview, Journal of Propulsion and Power, 5, Sept.-Oct. 1998.

5. G. Guerrini, C. Michaut, M. Dudeck and M. Bacal, Parameter Analysis of Three Small Ion Thrusters (SPT-20, SPT-50, A3), Proc. Second European Spacecraft Propulsion Conference, 2729 May, 1997, pp. 441-446.

6. V. Khayms and M. Martinez-Sanchez, Design of Miniaturized Hall Thruster for Microsatellites, AIAA paper 96-3291, July 1996.

7. V. M. Gavryushin and V. Kim, Effect of the characteristics of a magnetic field on the parameters of an ion current at the output of an accelerator with closed electron drift, Sov. Phys. Tech. Phys. 26(4), pp. 501-507.

8. A. D. Gallimore, M. L. Reichenbacher, C. Marrese, S-W Kim and J. E. Foster, Preliminary Characterization of a low Power End-Hall Thruster, AIAA paper 94-3012, June 1994.

9. H. R. Kaufman, R. S. Robinson, M. L. Day and T. W. Haag, End-Hall Thrusters, AIAA paper 90-2595, July 1990.

10. H. R. Kaufman, R. S. Robinson and R. I. Seddon, End-Hall ion source, J. Vac. Sci. Technol., A5(4) Jul.-Aug. 1987, pp. 2081-2084.

11. V. V. Zhurin, H. R. Kaufman and R. S. Robinson, Physics of closed drift thrusters, Plasma Sources Sci. Technol., 8, 1999, pp. 1-20.

12. N. J. Fisch, Y. Raitses, A. A. Litvak and L. A. Dorf, Design and Operation of Hall Thrusters with Segmented Electrodes AIAA 992572, (Los Angeles, CA , 1999). 
13. Y. Raitses, N. J. Fisch, L. A. Dorf and A. A. Litvak, Plume reduction in segmented electrode Hall thruster, J. Appl. Phys., 88(3), Aug. 2000.

14. Y. Raitses, J. Ashkenazy and M. Guelman, Propellant utilization in Hall Thrusters, J. Propul. Power, 14, 247, (1998).

15. J. Ashkenazy, Y. Raitses and G. Appelbaum, Low Power Scaling of Hall thrusters, Proc. Second European Spacecraft Propulsion Conference, 27-29 May, 1997, pp. 455-460.

16. A. I. Morozov, Dokl. Acad. Nauk, 163, 1965, p. 1363.

Plasma Diagnostics, ed. By W. LochteHoltgreven, North-Holland Publishing Comp., Amsterdam, 1968.
17. A. M. Kapulkin, A. D. Grishkevich and V. F. Prisnyakov, Outside Electric Field Thruster, IAF-94-S.3.422, $45^{\text {th }}$ Congress of the International Astronautical federation, Jerusalem, Israel, Oct. 1994.

A. A. Litvak and N. J. Fisch, Rayleigh-Taylor Type Instabilities in Hall Current Plasma Thruster, Mini-Conference on Plasma Propulsion Physics, APS-DPP meeting, Seattle, Nov. 1999.

18. W. A. Hargus, N. B. Meezan and M. A. Cappelli, A study of a Low Power Hall thruster transient Behavior, IEPC 97-058, 25 $5^{\text {th }}$ International Electric Propulsion Conference, Cleveland, OH, Aug. 1997.

19. L. Garrigues, A. Heron, J. C. Adam and J. P. Boeuf, Hybrid and PIC Models of a Stationary Plasma Thruster, Plasma Sources Sci. Technol., 9, 2000, 219 
The Princeton Plasma Physics Laboratory is operated by Princeton University under contract with the U.S. Department of Energy.

\author{
Information Services \\ Princeton Plasma Physics Laboratory \\ P.O. Box 451 \\ Princeton, NJ 08543
}

Phone: 609-243-2750

Fax: 609-243-2751

e-mail: pppl_info@pppl.gov

Internet Address: http://www.pppl.gov 